\section{Determining an acceptable number of cruise ships in a US national park based on incidents of ship- strikes with whales}

While national parks in the US are intended to conserve natural resources for the public to enjoy, those visitors can negatively impact resources: vehicles may collide with and kill wildlife; traffic can contribute to noise, water, and air pollution; human waste must be removed, etc. When these impacts are sufficiently large to threaten the sustainability of the resource, mangers should curtail the activities because it runs counter to the conservation mandate. However, when these impacts are smaller, managers must decide the impact level at which to curtail visitor volume or activities, which runs counter to the visitation mandate. The authors use the example of cruise-ship strikes with humpback whales in Glacier Bay National Park as a case study for this type of use-impact trade-off and the difficult decisions it creates.

Cruise ships transport over $95 \%$ of all visitors to Glacier Bay National Park each year and are thus integral for the NPS in meeting its mandate for visitor use and enjoyment. While relatively rare, lethal collisions between these ships and humpback whales that use the park occur. This requires managers to consider the level at which an impact - in this case the incidental whale mortality level — from an appropriate use of the area become unacceptably large?

To demonstrate the conflict generated by this issue, the authors modeled changes in cruise ship traffic and the population of humpback whales near the park. The National Park Service has been monitoring whales in the area since 1985 and during this time, only 2 whale strikes were reported. To provide a conservative estimate, the rate of actual ship strikes was set to be double that of reported strikes, or 0.000865 strikes per ship entering the bay to account for the possibility that strikes occurred but went undetected. The models estimated at maximum 8 additional strikes would occur over the next 30 years if the maximum allowable number of ships (visitors) were permitted to enter the park. This equated to approximately 1 additional dead whale for every 2,000,000 additional visitors. By comparison, it was estimated that 226 additional ship strikes would need to occur over that period for the whale population to stop growing, depending upon assumptions: an increase of 57 -times the current rate.

The question then becomes: should the level of mortality that would reduce population growth to stable serve as the threshold at which visitation is curtailed? If so, then many more whales could be struck before visitation is limited. If not, then what defines an acceptable impact, i.e., the number of dead whales, at which point visitation is limited. Whatever the decision-making process, the authors recommend that it be transparent and consider other stakeholders.

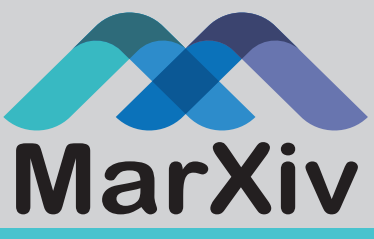

This is a summary of: Somewhere between acceptable and sustainable: When do impacts to resources become too large in protected areas?

Accessible at: https://marxiv.org/p6k9a

Author: Scott Gende, A. Noble Hendrix, Joshua Schmidt

Added to MarXiv: August 2018

Published: Biological Conservation, 2018

Suggested Citation: Social capital in fisheries governance. OCTO (2018). DOI: 10.31230/osf.io/dh2nu

See more MarXiv summaries at https://www.marxivinfo.org/ summaries

Join the MarXiv Summaries monthly newsletter at https:// oct.to/marxivsum

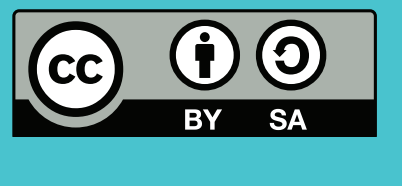

MarXiv is an ОСТO Initiative

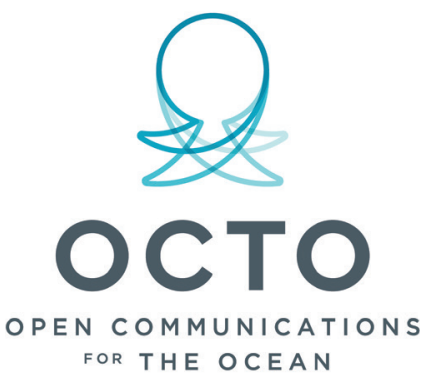

